\title{
The acquisition of asserted, presupposed, and pragmatically implied exhaustivity in Hungarian
}

\author{
Lilla Pintér \\ Pázmány Péter Catholic University \\ pinter.lilla@btk.ppke.hu
}

\begin{abstract}
The paper reports on three experiments in which the exhaustive interpretation of sentences containing the focus particle csak 'only', structural focus constructions, and sentences with neutral intonation and word order were investigated. The results obtained not only reveal the developmental trajectory of the adult-like comprehension of each sentence type, but also contribute to the discussion concerning the semantic or pragmatic nature of their exhaustive meaning component. As the three construction types were judged in different ways on a three-point scale, the findings appear to support the hypothesis according to which exhaustivity is part of the asserted content of sentences with csak 'only', it is context-independently presupposed in the case of structural focus, and in certain contexts it can arise as an implicature in the case of neutral utterances, as well.
\end{abstract}

Keywords: exhaustivity; focus particle; structural focus; acquisition; Hungarian

\section{Introduction}

A certain constituent is interpreted exhaustively if it identifies the whole set of individuals for which the predicate of the sentence holds and thus also excludes all the relevant alternatives. In Hungarian, there are numerous ways to express exhaustivity. The first option is the use of an exclusive particle such as csak 'only', the meaning of which is always associated with a syntactically and prosodically marked structural focus, as in the case of the focussed object of the example under (1). The second possibility is to formulate a sentence containing a structural focus (also referred to as a pre-verbal or identificational focus) without inserting a particle, which is claimed to be the equivalent of the English cleft construction (É. Kiss 1998), see (2). Note that in both cases, the focussed element bears a pitch accent (which is marked by small capitals throughout the paper) and moves into the position immediately preceding the tensed verb, as a consequence of which verbal modifiers (such as the particle meg in the examples) occur in the post-verbal region instead of the 
neutral pre-verbal slot. Additionally, one could also form cleft structures similarly to the English it-clefts (3), but these more rarely used constructions are not investigated in the present study. Finally, it is important to note that sentences with neutral intonation and word order (4) can also be interpreted exhaustively if the context strongly supports this reading. Moreover, if the object of (4) bears a pitch accent, it is a syntactically unmarked or in situ prosodic focus, whose primary role is to emphasise new information but it can also have an exhaustive reading in certain cases (for a detailed discussion, see Surányi 2011).

(1) Garfield csak Orson-T látogat-ta meg.

Garfield only Orson-ACC visit-PST PRT

'Garfield visited only Orson.'

(2) Garfield Orson-T látogat-ta meg.

Garfield Orson-ACC visit-PST PRT

'It is Orson who Garfield visited.'

(3) Orson az, aki-t Garfield meg-látogat-ott.

Orson that who-ACC Garfield PRT-visit-PST

'It is Orson who Garfield visited.'

(4) Garfield meg-látogat-ta Orson-t.

Garfield PRT-visit-PST Orson-ACC

'Garfield visited Orson.'

These constructions do not only differ in terms of usage frequency, but also in several other respects, such as the degree of cancellability and context-dependence, or the at-issue versus non-at-issue status of their exhaustive meaning component. In the following section, I attempt to give a brief overview of the main properties of each type tested in the current study.

The case of the particle csak is the least controversial. Based on the analysis of Horn (1969), Kenesei (1986) and Szabolcsi (1994) claim that there are two meaning components in sentences containing a focus particle, namely a presupposed and an asserted part. Thus, in the case of (1), the assertion is that Garfield visited no one other than Orson and it is presupposed that Garfield visited Orson. This latter part, which is also called the prejacent, was then suggested to be analysed as an existential presupposition (Horn 1996), as a conversational implicature (van Rooij \& Schulz 2007) and as a backgrounded entailment (Beaver \& Clark 2008; Roberts 2011). Importantly, however, it has never been the source of debate that it is the at-issue asserted content of these sentences that 
expresses exhaustivity. Two experimental studies have been carried out so far to compare adult native speakers' interpretation of sentences with csak to that of other construction types with an exhaustive inference (Geröcs et al. 2014; Onea \& Beaver 2011), both of which have supported the previous claim by finding strong rejection of utterances containing a focus particle in those contexts where the requirement of exhaustivity is not fulfilled. Nevertheless, testing children in various age groups is crucial as well, since the correct association of the meaning of pre-subject focus particles appeared to be difficult in several languages, among them English (Crain et al. 1994; Gualmini et al. 2003; Hackl et al. 2015; Paterson et al. 2005/2006), Mandarin Chinese (Notley et al. 2009; Zhou \& Crain 2010) and German (Berger \& Höhle 2012; Müller et al. 2011). Note that in these cases the associate of the particle is denoted merely by prosody, and, as has been showed by Gualmini et al. (2003), children at around the age of five cannot rely on prosodic cues when interpreting sentences containing only. As opposed to this, in Hungarian it can also be recognised on the basis of syntactic information, given that it always occurs in the immediately pre-verbal position.

Concerning the semantic characterisation of structural focus constructions, there are three conflicting approaches. Initially, Szabolcsi (1981a;b) and É. Kiss (1998) hypothesised the presence of a semantic operator expressing exhaustive identification as part of the truth-conditional content of these sentences. This was also the basic idea of the work of Horvath $(2005 ; 2007)$, who introduced an Exhaustive Identification Operator (EIOp) in order to explain both the exhaustive reading and the motivation behind the movement and the prosodic prominence of the focussed element. Alternatively, Kenesei (1986) proposed that the exhaustive interpretation of sentences with structural focus is not part of their asserted meaning but arises owing to a presupposed meaning component expressing that there is a set of individuals for which the predicate is true. The assertion of these utterances is the identification of this set by the focussed constituent. Thus, in the case of (2), the presupposition is that there is a unique set of friends who was visited by Garfield, and what is asserted is that this set consists of Orson. (For slightly modified versions of this claim see Bende-Farkas 2009; Kálmán \& van Leusen 1993; Szabolcsi 1994.) It is also important to note that Hungarian structural focus is often compared to it-clefts in English, the exhaustivity of which is also claimed to be a presupposition according to several authors (Abusch 2002; Büring \& Križ 2013; Gazdar 1979; Karttunen 1974; Percus 1997; among others). Both previous assumptions were, however, questioned by Wedgwood (2005), in 
whose analysis exhaustive interpretation is a conversational implicature in the case of sentences with and without structural focus alike. Therefore, in the cases of examples (2) and (4), we expect Orson to be the only one visited by Garfield merely as a function of the context, i.e., irrespective of the structural and prosodic properties of the utterances. Pragmatic reasoning is based either on Grice's (1975) Maxim of Quantity, or on Sperber and Wilson's (Sperber \& Wilson 1986; Wilson \& Sperber 2004) Relevance Theory. According to the former, an exhaustive reading arises when it is the most informative one; according to the latter, it emerges when it is the most relevant one. Although the examples with which Wedgwood (2005) and Onea (2007) attempted to verify the context-dependence of structural focus were convincingly refuted by É. Kiss (2010), the disproof of the pragmatic approach did not seem to be possible based solely on theoretical assumptions. This revelation led to a series of experiments.

The first experimental study investigating the exhaustivity of focus constructions in Hungarian was the work of Onea and Beaver (2011). They compared adult native speakers' interpretation of sentences with structural focus to that of sentences containing the particle csak by using a sentence-picture verification task in which participants could choose between the following three options: 'yes, and...', 'yes, but...', and 'no...' Since they found different response patterns with respect to the two construction types in the truth value judgement of non-exhaustive pictures, they concluded that while exhaustivity is in fact semantic in the case of $c s a k$, it is merely a pragmatic phenomenon in the case of structural focus. However, in a recently published study, Destruel et al. (2015) pointed out that this type of judgment only shows that exhaustivity is at-issue in the former case and non-at-issue in the latter one, and it does not provide any evidence concerning its semantic or pragmatic nature. Correspondingly, Velleman et al. (2012) argue that exclusives such as the particle only and structures like the $i$-cleft are inquiry terminating constructions, i.e., they are all marking utterances as complete answers to the Question Under Discussion, but the status of the exhaustive inference (at-issue or non-at-issue) is different in the two cases.

On the other hand, in a cross-linguistic study, Skopeteas and Fanselow (2011) found that in contrast with German, Spanish and Greek, in Hungarian exhaustivity expressed by focus is not a context-dependent pragmatic effect but rather an inherent structural property of the preverbal position. Note, however, that the reliability of their results regarding Hungarian is somewhat doubtful, as the focussed constituents of the test sentences they presented in the paper are bare nouns that could also function as verbal 
modifiers and thus appear in the pre-verbal position of neutral utterances as well, as has been shown by Komlósy (1994).

The question whether young children can differentiate between sentences with and without focus was also raised. The first acquisition study was carried out by Kas and Lukács (2013), who compared the focus sensitivity of six-year-olds and ten-year-olds to that of adults by collecting binary (true or false) judgments in a sentence-picture verification task. Interestingly, none of the groups evaluated structural focus constructions as false consistently in non-exhaustive contexts. Although the effect of focus was weaker than expected, the authors did not conclude that its exhaustivity cannot be a semantic meaning component, since they admitted that this design and especially the binary judgment used in the experiment is not suitable for distinguishing among different kinds of inferences and thus diagnosing the source of exhaustivity. Preschoolers' performance on sentences with structural focus was also tested by Balázs and Babarczy (2014), who argued in favour of the pragmatic account based on the observed correlations between the non-adult-like interpretation of structural focus and the immaturity of executive functions.

The methodologically most complex study is that of Gerôcs et al. (2014). Their first experiment was a truth value judgment task testing adults' interpretation of structural and prosodic focus constructions with limited response times (1000 $\mathrm{ms}$ in the so called "short condition" and $3000 \mathrm{~ms}$ in the "long condition"). It has been shown that the rejection of non-exhaustive scenarios was less frequent in the case of limited cognitive resources. Additionally, it has also been found that in the case of a preceding question, there is no significant difference between the judgment of sentences containing syntactically marked and unmarked foci. In the second experiment, which was a more indirect picture selection task, the interpretations of four construction types (csak, cleft, structural focus, and prosodic focus) were compared. Although the omission of the preceding question made the non-exhaustive pictures more acceptable in the case of both structural and prosodic focus, the former construction type was significantly more often interpreted exhaustively than the latter one, indicating that it is not the exact same inference that arises in the two cases. The hypothesis of Gerôcs et al. (2014) is that while exhaustivity is a conversational implicature in the case of prosodic focus, it is rather a conventional one in the case of structural focus. Thus, it is not merely the context, but the specific syntactic configuration of sentences containing structural focus that is triggering the implicature generation. Although this distinction can account for the different results obtained in the second 
experiment, this assumption is not entirely well-founded. According to the definition of Potts (2005), conventional implicatures are speaker-oriented entailments that are completely independent of at-issue entailments, and this hardly holds for exhaustivity inferences.

To summarise the properties of the focus constructions under investigation, exhaustivity can be experimentally proved to be a part of the asserted meaning only in the case of sentences with the focus particle csak. It is also beyond dispute that the exhaustive reading can arise as a conversational implicature in the case of prosodic focus and neutral sentences as well. On the contrary, it is highly controversial how to analyse the exhaustivity of structural focus. While the majority of theoretical works claim that it is presupposed, experimental studies carried out thus far (except for Skopeteas \& Fanselow 2011) seem to support the view that it is an implied and therefore strongly context-dependent content. The first type of argument in favour of this analysis is that adult speakers' judgements given in the case of structural focus differ from those of sentences with csak (Gerốcs et al. 2014; Onea \& Beaver 2011), whereas the second one is based on the observation that they do not differ considerably from the judgements of either prosodic focus (Gerôcs et al. 2014) or neutral sentences (Kas \& Lukács 2013; Onea \& Beaver 2011).

\section{The present study}

The purpose of the present study was to experimentally investigate how children comprehend sentences containing either the particle csak or structural focus, which are the two most frequently used focus constructions in Hungarian. Additionally, I also aimed to test utterances with neutral intonation and word order as a baseline. In each case, native speakers recruited from four age groups participated; therefore the acquisition path of the different kinds of exhaustive interpretation can also be examined. Crucially, there are two main aspects in which the current research considerably differs from studies carried out previously.

Firstly, in order to avoid the priming effect possibly occurring among structures expressing various kinds of exhaustivity, I conducted three experiments testing the construction types separately. Although this design is not suitable for the direct comparison of the results of different structures, the developmental trajectory of the interpretation of each construction can be revealed and thus conclusions can be drawn with respect to the semantic nature of their exhaustive meaning components as well. 
Secondly, I combined the commonly used sentence-picture verification task with a new version of the three-point scale instead of a binary truthvalue judgment, which proved not to be a proper method for distinguishing among non-at-issue meaning components such as presuppositions and implicatures. Since young children participated in the experiments, too, the number and type of the values of the scale had to be chosen carefully, and I decided to provide three non-verbally presented options. The idea of creating a Likert scale that can also be used by preschoolers was put forth by Katsos and Bishop (2011) and was also adopted by Balázs and Babarczy (2014). In both studies, the scale consisted of three differently sized strawberries. However, the assumption is that three smiley faces (a sad, a straight and a happy face) represent the values of the scale better, since the small strawberry of Katsos and Bishop, which is supposed to mean that the sentence does not match the picture, is also a reward.

\section{Hypotheses}

The first hypothesis concerns the order of the acquisition of the construction types under investigation. To access the adult-like interpretation of structural focus, children have to learn that the exhaustive meaning component of an utterance is associated with a particular syntactic position, which is assumed to be a more complex procedure given that in Hungarian the word-order is only constrained in the pre-verbal section of the predicate phrase, whereas it is free both in the topic field and in the post-verbal region (see É. Kiss 1981). Therefore it seems reasonable to assume that in this language a construction with a focus particle that lexically encodes exhaustivity is less effortful to process and thus easier to acquire. Moreover, if preschoolers are already sensitive to the status of a certain proposition relative to the question under discussion, the at-issue exhaustivity expressed by sentences with csak is presumably more available to them than the non-at-issue one conveyed by structural focus constructions.

According to the second hypothesis of the study, with a three-point Likert scale it is also possible to distinguish among exhaustive readings with different statuses (at-issue or non-at-issue) and different sources (asserted, presupposed or implied), and this can be detected as soon as the adult-like interpretation becomes available. More precisely, when the requirement of exhaustivity is violated, the predicted response is strong rejection in the case of at-issue asserted meaning components, while it is the middle option of the scale if the exclusivity of the focused element is conveyed via a non-at-issue presupposition or implicature. 
In the experiments using a sentence-picture verification task, not only the presence or absence of the exhaustive interpretation was tested, but it was also intended to be measured which constituent the participants associate this meaning component with. Therefore there were two critical conditions containing pictures violating the requirement of exhaustivity regarding the focussed and the non-focussed constituent of the test sentences, respectively. What seems valid to hypothesise is that the proportion of incorrect associations will be lower than it was found in the previously mentioned studies of English, German or Mandarin Chinese. Note that in those cases the associate of the focus particle is denoted merely by prosody, and, as has been shown by Gualmini et al. (2003), children at around the age of five cannot rely on prosodic cues when interpreting sentences containing only. As opposed to this, in Hungarian it can also be recognised on the basis of syntactic information, given that the focused element always occurs in the immediately pre-verbal position.

The last hypothesis to test is the possible effects of sentence types. The first factor that test sentences differed in was the presence or absence of the verbal particle. As the syntactic position of the particle is an important cue of the presence of a focus, presumably its post-verbal occurrence could facilitate the exhaustive interpretation of the utterances with structural focus, and probably also that of sentences with csak; whereas the particle's neutral pre-verbal position could signify that there is no focus in the utterance. Although theoretical assumptions do not suggest that subject and object foci should behave differently, this second factor was added for two reasons. On the one hand, several studies investigating focus particles found that comprehending exhaustivity associated with the subject is more problematic for young children; on the other hand, Kas and Lukács (2013) also found an unexpected subject-object asymmetry when testing structural focus.

\section{Experiments}

\subsection{Method}

In the three experiments, I used the exact same methodology, including design, picture stimuli, equipment and procedure, and it was only the structure of the presented sentences that differed in each case. Therefore the design and procedure employed for all three experiments are presented together. 


\subsubsection{Participants}

Monolingual Hungarian-speaking children in three different age groups were randomly selected from kindergartens and public primary schools, whereas adult controls participated on a voluntary basis. Table 1 shows the subjects whose data were included in the analyses based on their overall accuracy. (Responses of additional 6 preschoolers had to be excluded since they failed to complete more than $25 \%$ of the control and filler trials.)

Table 1: Participants in Experiment 1-3

\begin{tabular}{llccccc}
\hline Experiment & Age group & Number & Female & Male & Mean age & Range \\
\hline 1 & preschoolers & 15 & 6 & 9 & $5 ; 11$ & $5 ; 0-6 ; 8$ \\
& seven-year-olds & 15 & 11 & 4 & $7 ; 2$ & $6 ; 10-7 ; 5$ \\
& nine-year-olds & 15 & 10 & 5 & $9 ; 3$ & $8 ; 9-9 ; 11$ \\
& adults & 15 & 7 & 8 & $37 ; 5$ & $24 ; 10-56 ; 4$ \\
2 & preschoolers & 15 & 9 & 6 & $6 ; 2$ & $5 ; 8-6 ; 6$ \\
& seven-year-olds & 15 & 7 & 8 & $7 ; 5$ & $6 ; 9-8 ; 0$ \\
& nine-year-olds & 15 & 8 & 7 & $9 ; 7$ & $9 ; 0-10 ; 2$ \\
& adults & 15 & 11 & 4 & $42 ; 7$ & $21 ; 8-66 ; 5$ \\
& preschoolers & 15 & 10 & 5 & $6 ; 4$ & $5 ; 6-6 ; 9$ \\
& seven-year-olds & 15 & 9 & 6 & $7 ; 6$ & $6 ; 11-8 ; 2$ \\
& nine-year-olds & 15 & 7 & 8 & $9 ; 8$ & $9 ; 3-10 ; 2$ \\
& adults & 15 & 8 & 7 & $22 ; 10$ & $20 ; 1-28 ; 1$ \\
\hline
\end{tabular}

\subsubsection{Materials and design}

Within each experiment, all the test items were from the same type of structure: in Experiment 1 every sentence contained the particle csak; in Experiment 2 there were only structural focus constructions; whereas in Experiment 3 test sentences had neutral SVO word order with neutral intonation. In the case of each type of structure, I tested four different sentence types as both the grammatical function of the focussed constituent (subject or object) and type of the verb (with or without a verbal particle) were varied. All the test sentences of Experiment 1-3 can be found in the Appendix.

In the sentence-picture verification task conducted, test sentences were presented with a picture from one of the following four conditions: 
Control conditions:

(i) exhaustive condition: the sentence is exhaustively true of the presented picture

(ii) false condition: the sentence is false of the presented picture

Critical conditions:

(iii) non-exhaustive condition: the sentence is not exhaustively true of the presented picture

(iv) exhaustive condition with a distractor: the sentence is exhaustively true of the presented picture, but there is an additional distractor in the picture that can affect the judgment of the sentence if the participant incorrectly associates the exhaustive meaning with the nonfocussed constituent

The test trials are illustrated by the sentences under (5)-(7) and the pictures in Figure 1.

(5) Csak A NYUSZI emel-t-e fel a zászló-t.

Experiment 1 only the rabbit raise-PST-3SG PRT the flag-ACC csak 'only'

'Only the rabbit has raised the flag.'

(6) A NYUSZI emel-t-e fel a zászló-t.

Experiment 2

the rabbit raise-PST-3SG PRT the flag-ACC

structural focus

'It is the rabbit that has raised the flag.'

(7) A nyuszi fel-emel-t-e a zászló-t.

Experiment 3 the rabbit PRT-raise-PST-3SG the flag-ACC neutral SVO

'The rabbit has raised the flag.'

Each of the four conditions was represented by eight sentence-picture pairs, which gave rise to the total number of 32 test trials. As the Appendix displays, there were 16 test sentences, each of which was presented in one of the control conditions and also in one of the critical ones. In addition to these test trials, there were also four familiarisation trials and 24 filler trials. Because of the large number of items, I divided them into two lists, which were administered to the participants on two separate occasions. One half of the subjects received list A first and list B second, whereas the other half received them in the opposite order.

\subsubsection{Procedure}

Participants were tested individually by using a Toshiba Satellite L500-1EP notebook (screen size: 15.6 inches). Pairs of the auditory and visual stim- 


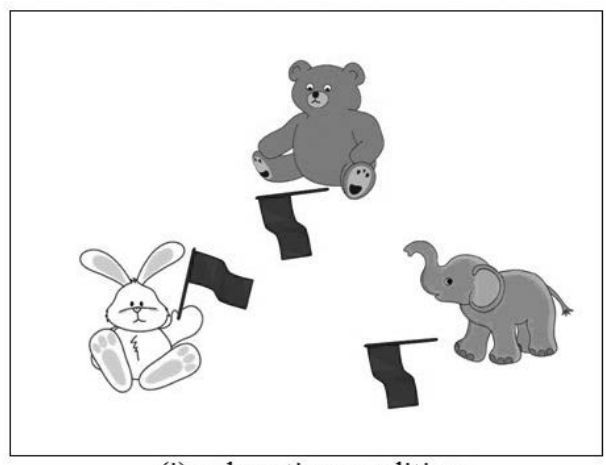

(i) exhaustive condition

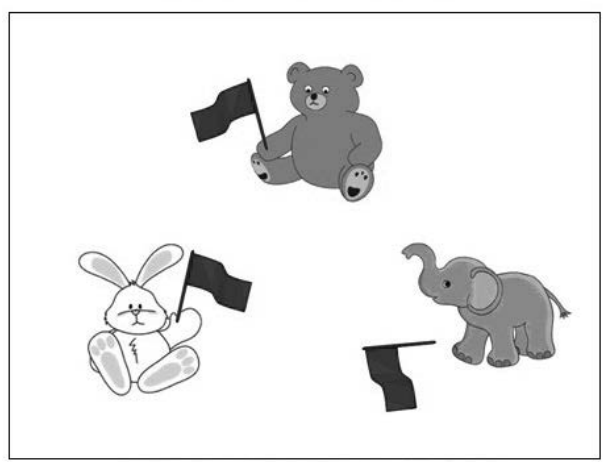

(iii) non-exhaustive condition

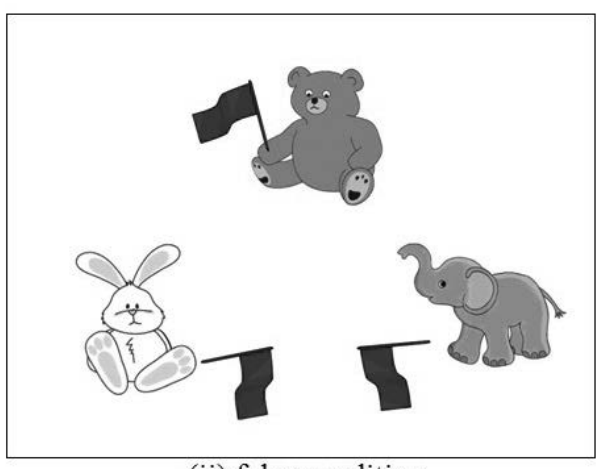

(ii) false condition

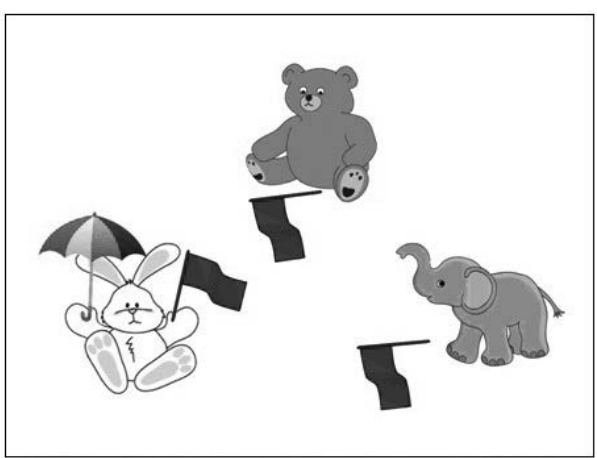

(iv) exhaustive condition with a distractor

Figure 1: The four test conditions

uli, i.e., the pre-recorded sentences and the pictures, were presented in a randomised order, using the SR Research Experiment Builder software. There were short familiarisation phases at the beginning of each session, in order to ensure that participants have understood the task itself and could correctly respond by using the scale. Crucially, I used sad, straight and happy smiley faces to differentiate between the options of "false", "inbetween" and "true" (Figure 2).
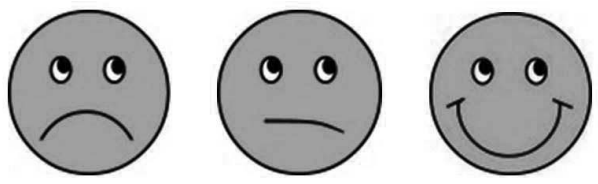

Figure 2: Smiley faces used as a three-point scale 
When testing children, the smiley faces were printed on cards and it was the experimenter who recorded their choice in the computer, whereas adults were asked to press the buttons with smiley stickers on them, so in their case I could also record the reaction times in addition to the responses.

\subsection{Results and discussion}

In all the experiments, I analysed responses given in various conditions by various age groups on the one hand, and reaction times measured in the adult control group on the other hand. For all the statistical analyses I used the software R (R Development Core Team 2014).

As the three response types formed an ordinal scale, I used nonparametric tests: Friedman's ANOVA to decide whether the frequency of certain response types differ significantly among the four conditions within one age group and Kruskal-Wallis Test for the between-group comparisons. For the post hoc pairwise comparisons, I used Exact Wilcoxon-Pratt Signed-Rank Tests in the former cases and Mann-Whitney U-Tests in the latter ones. I always adjusted the confidence intervals by using Bonferroni correction.

\subsubsection{Experiment 1 - The interpretation of sentences containing the particle csak 'only'}

The overall proportions of sad, straight, and happy smiley faces given in the test conditions of Experiment 1 are presented in Table 2.

Regarding the results of the critical non-exhaustive condition, i.e., the evaluation of those pictures in which the predicate holds for another referent in addition to the denotation of the focused constituent, the preferred response type was the sad face in each age group. On the other hand, the majority of the participants chose the happy face in the exhaustive with a distractor condition, indicating that in most of the trials they correctly recognised that in these cases the violation of exhaustivity did not concern the focused element within the scope of the particle. The first step of a more detailed analysis of the interpretation of sentences with csak is to compare the response patterns of the critical conditions to those of the control ones by considering the results of the Exact Wilcoxon-Pratt Signed-Rank Test displayed by Table 3 .

In the group of preschoolers, picture type had a significant effect according to Friedman ANOVA $\left(\chi^{2}(3, N=120)=235.79, p<.001\right)$. Moreover, the paired comparisons showed that responses given in the critical 
Table 2: Proportion of response types in Experiment 1

\begin{tabular}{|c|c|c|c|c|c|c|}
\hline \multirow[b]{2}{*}{ Age group } & \multirow[b]{2}{*}{$\begin{array}{l}\text { Type of } \\
\text { response }\end{array}$} & \multicolumn{4}{|c|}{ Conditions } & \multirow[b]{2}{*}{ Total } \\
\hline & & exhaustive & false & non-exhaustive & $\begin{array}{c}\text { exhaustive with } \\
\text { a distractor }\end{array}$ & \\
\hline \multirow[t]{3}{*}{ preschoolers } & $3-\odot$ & 96.0 & 5.0 & 23.0 & 82.0 & 51.50 \\
\hline & $2-\oplus$ & 0.0 & 7.0 & 9.0 & 1.0 & 4.25 \\
\hline & $1-:$ & 4.0 & 88.0 & 68.0 & 17.0 & 44.25 \\
\hline \multirow[t]{3}{*}{ seven-year-olds } & $3-\odot$ & 99.0 & 5.0 & 2.5 & 75.5 & 45.60 \\
\hline & $2-:)$ & 0.0 & 10.0 & 22.5 & 7.0 & 9.80 \\
\hline & $1-\odot$ & 1.0 & 85.0 & 75.0 & 17.5 & 44.60 \\
\hline \multirow[t]{3}{*}{ nine-year-olds } & $3-\odot$ & 94.0 & 4.0 & 1.0 & 91.0 & 47.50 \\
\hline & $2-\odot$ & 1.0 & 5.0 & 4.0 & 3.0 & 3.25 \\
\hline & $1-2$ & 5.0 & 91.0 & 95.0 & 6.0 & 49.25 \\
\hline \multirow[t]{3}{*}{ adults } & $3-\odot$ & 97.5 & 4.0 & 0.0 & 86.0 & 46.00 \\
\hline & $2-\odot$ & 0.0 & 1.0 & 20.0 & 7.0 & 7.00 \\
\hline & $1-:$ & 2.5 & 95.0 & 80.0 & 7.0 & 47.00 \\
\hline
\end{tabular}

non-exhaustive condition ( $\mathrm{Mdn}=1, \mathrm{SD}=.84$ ) differed significantly not only from those of the exhaustive $(\mathrm{Mdn}=3, \mathrm{SD}=.4)$ and exhaustive with a distractor $(\mathrm{Mdn}=3, \mathrm{SD}=.75)$ conditions, but also from those of the false one $(\mathrm{Mdn}=1, \mathrm{SD}=.49)$. Correspondingly, the exhaustive with a distractor condition also diverged from all the other picture conditions. These findings suggest that although the preferred response types were in line with the predicted patterns of an exhaustive interpretation, the evaluation of the sentences is less balanced with respect to the critical pictures. Crucially, however, the consistent use of the incorrect responses was infrequent, as there was only one child (the youngest one in the group, aged $5 ; 0)$ who gave happy faces to the puppet above chance level in the non-exhaustive trials, whereas no one opted for sad faces more than $60 \%$ of the trials in the exhaustive with a distractor condition.

The type of the presented picture also had a significant effect on the performance of seven-year-olds $\left(\chi^{2}(3, N=120)=283.16, p<.001\right)$. Nevertheless, as Table 3 shows, here only responses given in the exhaustive $(\mathrm{Mdn}=3, \mathrm{SD}=.18)$ and exhaustive with a distractor $(\mathrm{Mdn}=3, \mathrm{SD}=.77)$ conditions diverged from those of the non-exhaustive condition $(\mathrm{Mdn}=1$, $\mathrm{SD}=.5$ ), while there was no difference in comparison with the false (Mdn $=1, \mathrm{SD}=.51)$ picture type. This latter finding is fundamental, since it 
Table 3: Pairwise comparisons of the conditions tested in Experiment 1 using the Exact Wilcoxon-Pratt Signed-Rank Test

\begin{tabular}{|c|c|c|c|c|}
\hline & Preschoolers & Seven-year-olds & Nine-year-olds & Adults \\
\hline $\begin{array}{l}\text { exhaustive } \\
\text { vs. } \\
\text { non-exhaustive }\end{array}$ & $\begin{array}{l}Z=8.73 \\
r=.56 \\
p<.001\end{array}$ *** & $\begin{array}{l}Z=10.03 \\
r=.65 \\
p<.001\end{array}$ & $\begin{array}{l}Z=10.43 \\
r=.67 \\
p<.001\end{array}$ & $\begin{array}{l}Z=10.09 \\
r=.65 \\
p<.001^{* * *}\end{array}$ \\
\hline $\begin{array}{l}\text { false } \\
\text { vs. } \\
\text { non-exhaustive }\end{array}$ & $\begin{array}{l}Z=-4.58 \\
r=.3 \\
p<.001 \text { *** }\end{array}$ & $\begin{array}{l}Z=-2.3 \\
r=.15 \\
p=.29\end{array}$ & $\begin{array}{l}Z=1.25 \\
r=.08 \\
p=.12\end{array}$ & $\begin{array}{l}Z=-2.82 \\
r=.18 \\
p=.08\end{array}$ \\
\hline $\begin{array}{l}\text { non-exhaustive } \\
\text { vs. exh. with a } \\
\text { distractor }\end{array}$ & $\begin{array}{l}Z=7.68 \\
r=.5 \\
p<.001 \text { *** }\end{array}$ & $\begin{array}{l}Z=9.11 \\
r=.59 \\
p<.001\end{array}$ *** & $\begin{array}{l}Z=10.3 \\
r=.66 \\
p<.001\end{array}$ & $\begin{array}{l}Z=9.78 \\
r=.63 \\
p<.001\end{array}$ *** \\
\hline $\begin{array}{l}\text { exhaustive } \\
\text { vs. exh. with a } \\
\text { distractor }\end{array}$ & $\begin{array}{l}Z=3.41 r= \\
.22 p<.01 * *\end{array}$ & $\begin{array}{l}Z=5.28 \\
r=.34 \\
p<.001\end{array}$ & $\begin{array}{l}Z=1.23 \\
r=.08 \\
p=.68\end{array}$ & $\begin{array}{l}Z=2.93 \\
r=.19 \\
p=.18\end{array}$ \\
\hline $\begin{array}{l}\text { false } \\
\text { vs. exh. with } \\
\text { a distractor }\end{array}$ & $\begin{array}{l}Z=9.49 \\
r=.61 \\
p<.001 \text { *** }\end{array}$ & $\begin{array}{l}Z=9.12 \\
r=.59 \\
p<.001\end{array}$ *** & $\begin{array}{l}Z=10.12 \\
r=.65 \\
p<.001\end{array}$ & $\begin{array}{l}Z=10.11 \\
r=.65 \\
p<.001 \text { *** }\end{array}$ \\
\hline $\begin{array}{l}\text { exhaustive } \\
\text { vs. } \\
\text { false }\end{array}$ & $\begin{array}{l}Z=10.21 \\
r=.66 \\
p<.001 \text { *** }\end{array}$ & $\begin{array}{l}Z=10.26 \\
r=.66 \\
p<.001 \text { *** }\end{array}$ & $\begin{array}{l}Z=10.23 \\
r=.66 \\
p<.001 \text { *** }\end{array}$ & $\begin{array}{l}Z=10.55 \\
r=.68 \\
p<.001 \text { *** }\end{array}$ \\
\hline
\end{tabular}

proves that the fulfilment of the requirement of exhaustivity and the truth of the presuppositional content are equally necessary. With respect to the example under (5), this means that participants chose the same option in the case of the picture in which both the rabbit and the bear are raising a flag (iii) and where the rabbit is not raising the flag at all (ii). The remaining pairwise contrasts among the picture conditions also revealed a significant effect, parallel to the case of the younger age group.

Nine-year-olds responded similarly with respect to the correspondence between the non-exhaustive $(\mathrm{Mdn}=1, \mathrm{SD}=.27)$ and the false ( $\mathrm{Mdn}=$ $1, \mathrm{SD}=.49)$ conditions, yet the difference was not significant between the exhaustive with a distractor $(\mathrm{Mdn}=3, \mathrm{SD}=.5)$ and the exhaustive $(\mathrm{Mdn}=3, \mathrm{SD}=.45)$ picture types either. Thus, the slight uncertainty occurring in the two groups of younger participants also disappeared by the age of nine, and there were only a few exceptional cases of incorrect association of the exhaustive reading. As the other comparisons revealed differences between every other pair of picture types, the effect of condition 
was certainly also significant according to Friedman ANOVA $\left(\chi^{2}(3, N=\right.$ $120)=314.47, p<.001)$.

Correspondingly, in the case of adult native speakers, the condition had a strong effect $\left(\chi^{2}(3, N=120)=307.85, p<.001\right)$, and responses of the non-exhaustive condition $(\mathrm{Mdn}=1, \mathrm{SD}=.4)$ patterned with those of the false one $(\mathrm{Mdn}=1, \mathrm{SD}=.41)$, whereas the evaluation of the exhaustive with a distractor picture type $(\mathrm{Mdn}=3, \mathrm{SD}=.54)$ was in line with that of the exhaustive one $(\mathrm{Mdn}=3, \mathrm{SD}=.31)$.

Regarding the impact of the various sentence types, in the nonexhaustive critical condition neither the grammatical role of the focussed constituent (preschoolers: $Z=-.49, r=.06, p=.72$; seven-year-olds: $Z=-.37, r=.05, p=.92$; nine-year-olds: $Z=.02, r=.003, p=.82$; adults: $Z=-.63, r=.08, p=.75$ ), nor the presence or absence of the verbal particle (preschoolers: $Z=-1.64, r=.21, p=.11$; sevenyear-olds: $Z=-.73, r=.09, p=.56$; nine-year-olds: $Z=.02, r=$ $.003, p=.82$; adults: $Z=-1.27, r=.16, p=.34$ ) had a significant effect in any of the age groups. However, in the case of the exhaustive with a distractor condition, this holds only for the occurrence of the verbal particle (preschoolers: $Z=1.25, r=.16, p=.34$; seven-year-olds: $Z=-1.8, r=.23, p=.07$; nine-year-olds: $Z=1.5, r=.19, p=.19$; adults: $Z=.65, r=.08, p=.57$ ), while the grammatical role affected the performance of the group of preschoolers, as they gave significantly more correct answers (i.e., happy smiley faces) when judging subject focus sentences $(Z=3.63, r=.47, p<.01)$. The proportion of rejections -indicating an incorrect association - was only $5 \%$ in the case of sentences in which the particle was attached to a focussed subject, while it was $30 \%$ in the case of focussed objects. In the other age groups, there was no such difference (seven-year-olds: $Z=1.19, r=.15, p=.26$; nine-year-olds: $Z=1.04, r=.13, p=.31$; adults: $Z=1.31, r=.17, p=.22$ ).

Turning to the between-group comparisons, according to the KruskalWallis Test, the difference did not reach significance among the four age groups in the exhaustive $(H(3)=5.13, p=.16)$, false $(H(3)=6.45, p=$ $.09)$, and exhaustive with a distractor conditions $(H(3)=11.45, p=$ $.06)$. Responses given in the non-exhaustive condition varied among age groups $(H(3)=32.64, p<.001)$; however, the post hoc tests revealed that the contrast was significant only between the group of preschoolers and nine-year-olds $(p<.05)$. What is crucial here is that none of the children's groups performed in a non-adult-like fashion in the case of this construction type. 


\subsubsection{Experiment 2 - The interpretation of sentences containing structural focus}

Table 4 displays the overall responses to structural focus constructions of the four age groups.

Table 4: Proportion of response types in Experiment 2

\begin{tabular}{|c|c|c|c|c|c|c|}
\hline \multirow[b]{2}{*}{ Age group } & \multirow[b]{2}{*}{$\begin{array}{l}\text { Type of } \\
\text { response }\end{array}$} & \multicolumn{4}{|c|}{ Conditions } & \multirow[b]{2}{*}{ Tota } \\
\hline & & exhaustive & false & non-exhaustive & $\begin{array}{c}\text { exhaustive with } \\
\text { a distractor }\end{array}$ & \\
\hline \multirow[t]{3}{*}{ preschoolers } & $3-;$ & 97.0 & 4.0 & 64.0 & 81.0 & 62.00 \\
\hline & $2-:)$ & 1.0 & 13.0 & 23.0 & 7.0 & 11.00 \\
\hline & $1-:)$ & 2.0 & 83.0 & 13.0 & 12.0 & 27.00 \\
\hline \multirow[t]{3}{*}{ seven-year-olds } & $3-;$ & 100.0 & 1.0 & 27.0 & 69.0 & 49.25 \\
\hline & $2-;$ & 0.0 & 1.5 & 47.0 & 20.0 & 17.00 \\
\hline & $1-:$ & 0.0 & 97.5 & 26.0 & 11.0 & 33.75 \\
\hline \multirow[t]{3}{*}{ nine-year-olds } & $3-\odot$ & 98.0 & 1.5 & 18.0 & 66.0 & 46.00 \\
\hline & $2-:)$ & 2.0 & 2.5 & 75.0 & 32.5 & 28.00 \\
\hline & $1-\odot$ & 0.0 & 96.0 & 7.0 & 1.5 & 26.00 \\
\hline \multirow[t]{3}{*}{ adults } & $3-(;)$ & 99.0 & 4.0 & 13.0 & 81.0 & 49.25 \\
\hline & $2-\otimes$ & 1.0 & 3.0 & 79.0 & 17.0 & 25.00 \\
\hline & $1-: 2$ & 0.0 & 93.0 & 8.0 & 2.0 & 25.75 \\
\hline
\end{tabular}

The first finding that should be highlighted is that in this experiment the preferred response type of the non-exhaustive condition varied among age groups. While preschoolers mostly accepted sentences with structural focus despite the fact that on these pictures the requirement of exhaustivity was violated, school-aged children and adults responded with the middle option of the three-point scale in the majority of these critical trials. In the case of the exhaustive with a distractor pictures, the most frequently chosen face was the happy one irrespective of age of the participants. Let us consider what follows from the statistical comparisons of the pairs of the tested conditions by scrutinizing the data in Table 5 .

Although the response patterns of preschoolers varied throughout the conditions and this effect was significant according to the Friedman ANOVA test $\left(\chi^{2}(3, N=120)=250.06, p<.001\right)$ as well, the evaluation of the non-exhaustive $(\mathrm{Mdn}=3, \mathrm{SD}=.71)$ picture type differed only from those of the false $(\mathrm{Mdn}=1, \mathrm{SD}=.5)$ and exhaustive $(\mathrm{Mdn}=3, \mathrm{SD}=.27)$ ones, but not from that of the exhaustive with a distractor $(\mathrm{Mdn}=3$, SD 
Table 5: Pairwise comparisons of the conditions tested in Experiment 2 using the Exact Wilcoxon-Pratt Signed-Rank Test

\begin{tabular}{lllll}
\hline & Preschoolers & Seven-year-olds & Nine-year-olds & Adults \\
\hline exhaustive & $Z=5.98$ & $Z=9$ & $Z=9.64$ & $Z=9.91$ \\
vs. & $r=.39$ & $r=.58$ & $r=.62$ & $r=.64$ \\
non-exhaustive & $p<.001 * * *$ & $p<.001 * * *$ & $p<.001 * * *$ & $p<.001 * * *$ \\
\hline false & $Z=-9.34$ & $Z=-8.84$ & $Z=-9.53$ & $Z=-8.97$ \\
vs. & $r=.6$ & $r=.57$ & $r=.61$ & $r=.58$ \\
non-exhaustive & $p<.001 * * *$ & $p<.001 * * *$ & $p<.001 * * *$ & $p<.001 * * *$ \\
\hline non-exhaustive & $Z=2.78$ & $Z=5.98$ & $Z=6.59$ & $Z=8.42$ \\
vs. exh. with a & $r=.18$ & $r=.38$ & $r=.43$ & $r=.54$ \\
distractor & $p=.51$ & $p<.001 * * *$ & $p<.001 * * *$ & $p<.001 * * *$ \\
\hline exhaustive & $Z=4.08$ & $Z=6.06$ & $Z=6.17$ & $Z=4.69$ \\
vs. exh. with a & $r=.26$ & $r=.39$ & $r=.4$ & $r=.3$ \\
distractor & $p<.01 * *$ & $p<.001 * * *$ & $p<.001 * * *$ & $p<.001 * * *$ \\
\hline false & $Z=9.39$ & $Z=9.75$ & $Z=9.83$ & $Z=9.94$ \\
vs. exh. with & $r=.61$ & $r=.63$ & $r=.64$ & $r=.64$ \\
a distractor & $p<.001 * * *$ & $p<.001 * * *$ & $p<.001 * * *$ & $p<.001 * * *$ \\
\hline exhaustive & $Z=10.16$ & $Z=10.82$ & $Z=10.67$ & $Z=10.54$ \\
vs. & $r=.66$ & $r=.7$ & $r=.69$ & $r=.68$ \\
false & $p<.001 * * *$ & $p<.001 * * *$ & $p<.001 * * *$ & $p<.001 * * *$ \\
\hline
\end{tabular}

$=.67)$ one. That is, they did not judge the sentence-picture pairs as false consistently in any of the critical conditions, yet in both cases there were some instances of rejections leading into a distribution that also differs from the responses of the undoubtedly true exhaustive condition. In line with the results of Kas \& Lukács (2013) and Balázs \& Babarczy (2014), these findings suggest that children at the age of six do not associate an exhaustive reading with the constituent occurring in the structural focus position of the sentence, and there is a continuous increase of exhaustive interpretations with age. Moreover, from this task involving an exhaustive with a distractor picture type as well, it can also be concluded that in the case of structural focus constructions, scenarios that violate exclusivity are not particularly problematic to preschoolers in general, and apparently they only tend to check whether the assertion of the utterance is true or false.

Responses given by seven-year-olds were also affected by condition $\left(\chi^{2}(3, N=120)=273.5, p<.001\right)$, furthermore, within this group the 
difference was strongly significant between each of the six pairs of the exhaustive ( $\mathrm{Mdn}=3, \mathrm{SD}=0)$, exhaustive with a distractor $(\mathrm{Mdn}=3$, $\mathrm{SD}=.68)$, non-exhaustive $(\mathrm{Mdn}=2, \mathrm{SD}=.73)$, and false $(\mathrm{Mdn}=1, \mathrm{SD}=$ .22) picture types. Recalling the proportion of response types summarised in Table 4, consistency was the lowest in the non-exhaustive condition, where none of the options were chosen in more than $50 \%$ of the cases. However, the analysis of the individual responses revealed that out of the fifteen participants, twelve opted for the straight or sad face more than $60 \%$ of these trials, two were performing at chance level, and only one child did not use any other option but the happy face. Presumably it was also hard for them to differentiate between the degrees of rejection, which resulted in an even vaguer reflection of their interpretational preferences.

Results of the group of nine-year-olds were similar according to the global analysis $\left(\chi^{2}(3, N=120)=289.67, p<.001\right)$, as well as according to the pairwise tests among the exhaustive $(\mathrm{Mdn}=3, \mathrm{SD}=.13)$, exhaustive with a distractor $(\mathrm{Mdn}=3, \mathrm{SD}=.52)$, non-exhaustive $(\mathrm{Mdn}=2, \mathrm{SD}=$ $.49)$, and false ( $\mathrm{Mdn}=1, \mathrm{SD}=.3)$ conditions. What has to be emphasised here in the first place is that both the overall judgment and the preferred response type of the non-exhaustive picture type robustly diverged from those of the false one, indicating that although structural focus constructions are not completely acceptable in these critical contexts, they are also not as problematic here as in the case of the pictures that are incompatible with the assertion of the sentence. Getting back to the example under (6) again, what happened is that the great majority of participants responded with the straight smiley face when the requirement of exhaustivity was violated, i.e., in the case of picture type (iii) and sometimes also in the case of type (iv), whereas they rejected the test sentences by giving a sad face when the asserted meaning, i.e., that the rabbit has raised a flag, was not true (ii).

That is exactly what was found in the adult control group, i.e. the effect of condition was strongly significant, similarly to the difference between each pair of conditions. Regarding the most frequently chosen option of the scale, the only correspondence that can be found is the preference for happy faces in the exhaustive $(\mathrm{Mdn}=3, \mathrm{SD}=.09)$ and exhaustive with a distractor $(\mathrm{Mdn}=3, \mathrm{SD}=.47)$ conditions. In the non-exhaustive $(\mathrm{Mdn}=2, \mathrm{SD}=.47)$ condition, most of the participants opted for the straight face, as opposed to the false $(\mathrm{Mdn}=1, \mathrm{SD}=.43)$ pictures, in the case of which they chose the sad one indicating total rejection.

It holds for each age group that neither the grammatical role of the focussed constituent (preschoolers: $Z=-.39, r=.05, p=.76$; seven- 
year-olds: $Z=.27, r=.04, p=.83$; nine-year-olds: $Z=0, r=0, p=1$; adults: $Z=-.79, r=.1, p=.5$ ), nor the presence or absence of the verbal particle (preschoolers: $Z=1.2, r=.15, p=.27$; seven-year-olds: $Z=.5, r=.07, p=.68$; nine-year-olds: $Z=.73, r=.09, p=.59$; adults: $Z=.59, r=.08, p=.65)$ affected the interpretation of the non-exhaustive picture type. This was found in the exhaustive with a distractor condition too, since no differences were detected between the responses given in the case of subject and object focus (preschoolers: $Z=-.17, r=.02, p=.99$; seven-year-olds: $Z=2.86, r=.37, p=.053$; nine-year-olds: $Z=1.08, r=$ $.14, p=.3$; adults: $Z=2.3, r=.3, p=.2$ ) or in the case of verbs with and without a particle (preschoolers: $Z=.78, r=.1, p=.55$; seven-yearolds: $Z=.18, r=.02, p=.96$; nine-year-olds: $Z=.63, r=.08, p=.68$; adults: $Z=-.31, r=.04, p=.81)$. In the case of this second critical picture type, it is important to emphasise that in each age group, the ratio of happy smiley faces was the highest, and as there is no clear tendency to the exhaustive interpretation according to sentence types either, it is reasonable to assume that the significant difference in comparison with the judgment of the exhaustive condition is merely due to occasional mistakes or misinterpretations.

Crucially, the response patterns of the four age groups did not differ significantly in the exhaustive $(H(3)=3.39, p=.34)$ and exhaustive with a distractor $(H(3)=9.38, p=.15)$ conditions, in contrast with the false $(H(3)=19.76, p<.01)$ and non-exhaustive $(H(3)=53.24, p<.001)$ ones. While the pairwise comparisons used as post hoc analyses did not show any variation among groups in the false condition, there was a marked difference in the non-exhaustive one, where the performance of preschoolers significantly differed from that of the other age groups (all three $p<.001$ ). Recall that in the case of the youngest participants, not the straight but the happy face was the most frequently chosen one in this condition, which indicates that they either did not process the exhaustive meaning component of the sentence or did not observe the presented pictures carefully enough. The response pattern of seven-year-olds was quite inconsistent as well, but they chose the middle option in the majority of these trials just like nine-year-olds and adults did. Regarding the exhaustive with a distractor condition, it is worth emphasising that although its interpretation was adult-like in all three of children's age groups, both in the case of sevenyear-olds and in the case of nine-year-olds the sad or the straight face was given to the puppet in around $30 \%$ of the trials. This ratio suggests that although they are already aware of the fact that sentences with structural focus express exhaustivity, they tend to be uncertain about which constituent they should associate this reading with. 


\subsubsection{Experiment 3 - The interpretation of sentences with neutral intonation and word order}

The overall proportion of responses chosen in Experiment 3 is presented in Table 6.

Table 6: Proportion of response types in Experiment 3

\begin{tabular}{|c|c|c|c|c|c|c|}
\hline \multirow[b]{2}{*}{ Age group } & \multirow[b]{2}{*}{$\begin{array}{l}\text { Type of } \\
\text { response }\end{array}$} & \multicolumn{4}{|c|}{ Conditions } & \multirow[b]{2}{*}{ Total } \\
\hline & & exhaustive & false & non-exhaustive & $\begin{array}{c}\text { exhaustive with } \\
\text { a distractor }\end{array}$ & \\
\hline \multirow[t]{3}{*}{ preschoolers } & $3-(;)$ & 98.0 & 3.0 & 81.0 & 86.0 & 67.00 \\
\hline & $2-\dot{\theta}$ & 0.0 & 8.0 & 13.0 & 10.0 & 7.75 \\
\hline & $1-:)$ & 2.0 & 89.0 & 6.0 & 4.0 & 25.25 \\
\hline \multirow[t]{3}{*}{ seven-year-olds } & $3-(;)$ & 97.0 & 2.0 & 72.0 & 84.0 & 63.75 \\
\hline & $2-:)$ & 2.0 & 14.0 & 22.0 & 14.0 & 13.00 \\
\hline & $1-:)$ & 1.0 & 84.0 & 6.0 & 2.0 & 23.25 \\
\hline \multirow[t]{3}{*}{ nine-year-olds } & $3-\odot$ & 98.0 & 2.0 & 50.0 & 52.5 & 50.50 \\
\hline & $2-\dot{\theta}$ & 1.0 & 7.0 & 47.5 & 42.5 & 24.50 \\
\hline & $1-:$ & 1.0 & 91.0 & 2.5 & 5.0 & 25.00 \\
\hline \multirow[t]{3}{*}{ adults } & $3-\odot$ & 94.0 & 1.0 & 81.0 & 87.0 & 65.75 \\
\hline & $2-\odot$ & 5.0 & 4.0 & 19.0 & 12.0 & 10.00 \\
\hline & $1-:$ & 1.0 & 95.0 & 0.0 & 1.0 & 24.25 \\
\hline
\end{tabular}

Comparing the results of preschoolers, seven-year-olds and adults, no difference can be found with respect to the preferred response types in any of the tested conditions. Most importantly, participants from these age groups accepted the critical sentence-picture pairs in the great majority of the trials, providing evidence in favour of the view according to which there is no requirement of exhaustivity per se in the case of neutral SVO sentences. On the contrary, in the group of nine-year-old children, there was no such preference, as only one half of the responses given in the critical conditions consisted of happy faces. The outcomes of the statistical analyses of the four age groups' data are summarised in Table 7.

While the type of the presented picture affected preschoolers' responses to a great extent according to Friedman ANOVA $\left(\chi^{2}(3, N=\right.$ $120)=268.44, p<.001)$, not all of the pairwise contrasts were significant. Considering the case of the non-exhaustive $(\mathrm{Mdn}=3, \mathrm{SD}=.55)$ condition, it differed from the false $(\mathrm{Mdn}=1, \mathrm{SD}=.44)$ and the exhaustive $(\mathrm{Mdn}=$ 
Table 7: Pairwise comparisons of the conditions tested in Experiment 3 using the Exact Wilcoxon-Pratt Signed-Rank Test

\begin{tabular}{lllll}
\hline & Preschoolers & Seven-year-olds & Nine-year-olds & Adults \\
\hline exhaustive & $Z=4.13$ & $Z=5.02$ & $Z=7.6$ & $Z=3.23$ \\
vs. & $r=.27$ & $r=.32$ & $r=.49$ & $r=.21$ \\
non-exhaustive & $p<.01 * *$ & $p<.001 * * *$ & $p<.001 * * *$ & $p<.05 *$ \\
\hline false & $Z=-9.66$ & $Z=-9.56$ & $Z=-9.51 r=$ & $Z=-10.11$ \\
vs. & $r=.62$ & $r=.62$ & .61 & $r=.65$ \\
non-exhaustive & $p<.001 * * *$ & $p<.001 * * *$ & $p<.001 * * *$ & $p<.001$ *** \\
\hline non-exhaustive & $Z=1.32$ & $Z=2.37$ & $Z=.18$ & $Z=1.24$ \\
vs. exh. with a & $r=.09$ & $r=.15$ & $r=.01$ & $r=.08$ \\
distractor & $p=.33$ & $p=.07$ & $p=.99$ & $p=.41$ \\
\hline exhaustive & $Z=3.39$ & $Z=3.11$ & $Z=7.18$ & $Z=1.73$ \\
vs. exh. with a & $r=.22$ & $r=.2$ & $r=.46$ & $r=.11$ \\
distractor & $p<.05 *$ & $p<.05 *$ & $p<.001 * * *$ & $p=.06$ \\
\hline false & $Z=9.96$ & $Z=9.91$ & $Z=9.49$ & $Z=10.23$ \\
vs. exh. with & $r=.64$ & $r=.64$ & $r=.61$ & $r=.66$ \\
a distractor & $p<.001 * * *$ & $p<.001 * * *$ & $p<.001 * * *$ & $p<.001$ *** \\
\hline exhaustive & $Z=10.38$ & $Z=10.16$ & $Z=10.45$ & $Z=10.51$ \\
vs. & $r=.67$ & $r=.66$ & $r=.68$ & $r=.68$ \\
false & $p<.001 * * *$ & $p<.001 * * *$ & $p<.001 * * *$ & $p<.001 * * *$ \\
\hline
\end{tabular}

$3, \mathrm{SD}=.26)$ types (though from the latter one only to a smaller degree), whereas it did not differ from the exhaustive with a distractor $(\mathrm{Mdn}=3$, $\mathrm{SD}=.49)$ condition. The difference between the exhaustive and the critical pictures was quite unexpected, given that the most frequent response was the happy face in each of these conditions. Nevertheless, the analysis of individual patterns suggests that it is a consequence of the performance of one participant (a girl aged 6;2), who consistently opted for the middle option in the case of the pictures where the requirement of exhaustivity was not met. In the case of all the other preschoolers, the ratio of acceptances was above the level of chance.

Unpredictably, the judgments of seven-year-olds appeared to be less adult-like than those of preschoolers, as in this age group the ratio of rejection was somewhat higher in both of the critical conditions. Even so, condition still had a significant effect $\left(\chi^{2}(3, N=120)=270.52, p<.001\right)$ and Wilcoxon tests also provided similar results, i.e., they did not show any difference between the critical non-exhaustive $(\mathrm{Mdn}=3, \mathrm{SD}=.59)$ and 
exhaustive with a distractor $(\mathrm{Mdn}=3, \mathrm{SD}=.42)$ conditions, while both of these diverged from the exhaustive $(\mathrm{Mdn}=3, \mathrm{SD}=.24)$ and especially from the false $(\mathrm{Mdn}=1, \mathrm{SD}=.46)$ picture type.

Responses given by nine-year-olds were also affected by condition $\left(\chi^{2}(3, N=120)=264.87, p<.001\right)$, moreover, the results of the pairwise comparisons showed the exact same patterns as in the previous cases, i.e., the evaluation of the non-exhaustive $(\mathrm{Mdn}=2.5, \mathrm{SD}=.55)$ and exhaustive with a distractor $(\mathrm{Mdn}=3, \mathrm{SD}=.59)$ conditions did not diverge, whereas all the other picture pairs including the exhaustive $(\mathrm{Mdn}=3, \mathrm{SD}$ $=.2)$ and false $(\mathrm{Mdn}=1, \mathrm{SD}=.39)$ controls differed significantly from each other. However, as the proportion of response types displayed in Table 6 suggested, in this age group there was a lack of a steady preference for acceptance or rejection if the requirement of exhaustivity was violated, irrespective of the position of the constituent this reading could be associated with. According to the analysis of responses given by individual participants, in the non-exhaustive condition the happy and the straight/sad face was chosen consistently (i.e., in more than $60 \%$ of the trials) by six children each, and only three children performed at the level of chance. The case of the exhaustive with a distractor condition is even clearer: out of the fifteen participants, eight accepted the neutral SVO sentences and seven did not, so no one responded at chance-level. Therefore it can be concluded that there was more between-subject than within-subject variation in the performance of nine-year-olds. What needs to be accounted for is the unexpectedly high ratio of constant rejections. On the one hand, it seems reasonable to predict that it arises as a result of the overgeneralisation of the recently acquired rule that sentences without a focus particle can also be interpreted exhaustively. If this is the case, for children in this age group the most challenging part of distinguishing among structures expressing different kinds of exhaustivity is to take contextual factors into consideration. On the other hand, it is also possible that the non-adultlike performance of almost half of the participants is due to some kind of task effect. Presumably, it was their attempt to perfectly judge the sentence-picture pairs that made them give a straight face at best in the case of the tiniest mismatch. This latter view can also be supported by the results of the control and filler conditions, as nine-year-old participants barely made any mistake.

To decide whether an exhaustivity implicature should have been calculated in this context, let us consider the adult control group's data, in the case of which, too, the picture condition played a significant role according to Friedman ANOVA $\left(\chi^{2}(3, N=120)=298.29, p<.001\right)$, but post hoc 
analyses yielded results that are dissimilar to those of the children's three groups. In line with the preferred response types, a strongly significant difference was only found when false $(\mathrm{Mdn}=1, \mathrm{SD}=.27)$ pictures were contrasted with exhaustive ( $\mathrm{Mdn}=3, \mathrm{SD}=.28$ ), non-exhaustive (Mdn $=3, \mathrm{SD}=.39)$ and exhaustive with a distractor $(\mathrm{Mdn}=3, \mathrm{SD}=.4)$ ones. The fact that adults mostly accepted the test sentences in both of the critical conditions indicates that there was no contextually triggered implicature generation that could have led to an exhaustive interpretation of the utterances.

Nonetheless, investigating the effect of sentence types is crucial here, especially the case of the subject and the object as they occur in different syntactic positions in this experiment. As has been mentioned before, I rephrased the previously used test sentences by giving them a neutral SVO word order, therefore the former subject foci are in this case in the sentence-initial topic position, whereas the former object foci are in the sentence-final position, which is also the place of in situ prosodic foci in Hungarian. Even though the intonation of the test sentences was also intended to be neutral, we cannot rule out the possibility that native speakers would interpret these objects exhaustively more often. Apparently, this is exactly what was found in the non-exhaustive condition, since adult participants gave significantly fewer happy faces $(Z=3.64, r=.47, p<.01)$ in the case of the former object focus sentences, where the pictures illustrated a scenario of an agent performing an action with two of the items, e.g. a bear that is pulling a sledge and a train. That is, the acceptance ratio was only $68 \%$ if the predicate did not only hold with respect to the denotation of the postverbal constituent, whereas it was $93 \%$ if the topicalized element violated exhaustivity. In other age groups, the difference between these sentence types was not significant (preschoolers: $Z=$ $1.41, r=.18, p=.2$; seven-year-olds: $Z=2, r=.26, p=.13$; nine-yearolds: $Z=1.16, r=.15, p=.31$ ). Interestingly, there was no such effect in the case of the exhaustive with a distractor condition either (preschoolers: $Z=-.36, r=.05, p=.66$; seven-year-olds: $Z=-1.29, r=.17, p=.3$; nine-year-olds: $Z=.43, r=.06, p=.72$; adults: $Z=.57, r=.07, p=$ $.72)$, although here the alternatives of the objects were depicted in case of the initially subject focus sentences (see picture (iv) of Figure 1 in the case of test sentence under (7)). Similarly to the previous experiments, there was no impact of the presence or absence of the verbal particle either in the non-exhaustive (preschoolers: $Z=.64, r=.08, p=.61$; seven-year-olds: $Z=.57, r=.07, p=.64$; nine-year-olds: $Z=1.13, r=.15, p=.3$; adults: $Z=1.94, r=.25, p=.09)$ or in the exhaustive with a distractor 
condition (preschoolers: $Z=.85, r=.11, p=.39$; seven-year-olds: $Z=1.34, r=.17, p=.2$; nine-year-olds: $Z=.76, r=.1, p=.54$; adults: $Z=.62, r=.08, p=.7)$.

Regarding the between-group comparisons, there was no difference in the case of the exhaustive $(H(3)=4.48, p=.22)$ and false $(H(3)=$ $8.82, p=.19)$ control conditions, as opposed to the critical non-exhaustive $(H(3)=33.56, p<.001)$ and exhaustive with a distractor $(H(3)=$ $54.12, p<.001)$ conditions. The post hoc analyses showed that both in the non-exhaustive and in the exhaustive with a distractor condition, the observed difference was significant when comparing the group of nine-yearolds to each of the other three groups (all three $p<.01$ in each critical condition).

\subsection{General discussion}

As in the three experiments different construction types were evaluated by different participants, no direct comparisons can be made across the tested structures. Yet it is possible to discuss the developmental paths and response patterns detected in one experiment in relation to those of the other constructions.

Regarding the issue of acquisition, the first hypothesis was borne out as it was in fact the case that the adult-like interpretation of csak precedes that of structural focus. While in the former case even preschoolers rejected non-exhaustive sentence-picture pairs, in the latter one they predominantly opted for acceptance in the critical scenarios. Furthermore, in Experiment 2 seven-year-olds were also uncertain when judging structural focus constructions in relation to pictures violating exhaustivity. It was the group of nine-year-olds that first showed indisputable access to the exhaustive reading in the case of each construction type. The problem at this age was rather the overgeneralisation of exclusivity that led to a rejective response also when the predicate did not solely hold for a nonfocussed constituent, i.e., in the exhaustive with a distractor condition of Experiment 2 and especially in both of the critical conditions of Experiment 3. Nevertheless, in the former experiment the occasional rejections were based on the erroneous association of the exhaustive meaning, while in the latter almost one half of the nine-year-old participants computed an exhaustivity implicature as it would have been triggered by a constituent occurring either in the topic position or in the post-verbal field of the sentence. This latter strategy could be valid when sufficient contextual support is provided; however, in this experimental setting this was 
certainly not the case as shown by the high acceptance rate of the adult control group. The fact that many children did not take contextual factors into account also suggests that the adult-like understanding of implied exhaustivity is an even later developmental result than that of the presupposed one. Yet the verification of this assumption needs further evidence, in particular through conducting experiments in which the generation of an exhaustivity implicature is undoubtedly motivated by the context.

Participants' use of the three response types confirmed the second hypothesis as well, as different values of the scale were chosen when various kinds of exhaustive readings were conveyed by the test sentences. In the non-exhaustive condition of Experiment 1, utterances containing the particle $c s a k$ were rejected with a sad smiley face in the great majority of the trials. Moreover, in the group of seven-year-olds, nine-year-olds and adults, the evaluation of this critical condition did not significantly differ from that of the false one, indicating that participants detected a violation of the atissue asserted content in each case. As opposed to this, responses chosen in these picture conditions always diverged in the case of structural focus constructions of Experiment 2, since sad faces were given to the puppet only in the false control condition. Non-exhaustive scenarios were rather judged by the middle option of the scale, suggesting that although the use of structural focus is not entirely appropriate in contexts in which the requirement of exhaustivity is not fulfilled, it is not unacceptable either. The systematic use of the straight face was first observed in the group of nine-year-olds, which is not surprising considering the previously described developmental process. In the earliest stage of the noteworthy appearance of the non-rejective responses, seven-year-old children could not clearly decide between the two values differing in the strength of the opposition, although the straight face was the most frequently chosen one in this group too. These results provided further evidence in favour of the non-at-issue status of the exhaustivity of the structural focus. Although the findings are completely in line with the predictions of the presupposition analysis as well, they cannot be regarded as decisive with respect to the question of the source of exhaustivity expressed by structural focus, given that the middle option was also chosen by nine-year-olds if implied exclusivity was violated in Experiment 3. Nevertheless, these experimental outcomes are crucial from a methodological point of view, as they validated the use of a three-point scale consisting of smiley faces.

As far as the association with focus is concerned, the high ratio of happy faces given in the exhaustive with a distractor condition supported the hypothesis that if the focussed constituent is easier to detect by means 
of syntactic cues, even young children can connect the exclusion of the alternatives with its denotation. Although errors were considerably less frequent in all the three experiments than in the case of only in English, in the exhaustive with a distractor condition of Experiment 1 it turned out that if preschoolers rejected the sentences with csak, they typically did so in the case of focussed objects, which is the exact opposite of the pattern observed in other languages. The difference from English, Mandarin Chinese or German is probably due to the fact that in Hungarian the focus marking of subjects and objects is equally salient as in both cases it includes a movement to the pre-verbal position. Additionally, the slight preference for the subject to be the associate of the focus particle can possibly be explained by the hypothesis of Gualmini et al. (2003), according to which the animacy of the denotation of the constituents can also influence the decision of small children when searching for the element the alternatives of which they exclude. Interestingly, straight and sad faces were also chosen occasionally in the exhaustive with a distractor condition of Experiment 2. A possible explanation could be that in these particular cases participants understood the test sentences as having sentential focus instead of narrow contrastive focus. Examples in which there is a focussed subject but the whole sentence is interpreted as focus have already been mentioned by É. Kiss (1998) and were also discussed in details by Kenesei (2006). Therefore it might be the case that the sentence under (6) was occasionally comprehended as 'what happened was that the rabbit has raised the flag', which expresses the exclusion of the alternatives of the rabbit, but could also convey that 'nothing else happened' which would make the exhaustive with a distractor pictures less acceptable as well.

This latter question is already bears on the last group of hypotheses attempting to predict how particular syntactic properties of the test sentences can affect the accessibility of the exhaustive reading. The grammatical function of the focussed constituent had an impact in two cases, firstly in preschoolers' previously mentioned asymmetric behaviour in the case of csak in Experiment 1, and secondly in adults' preference to interpret non-focussed post-verbal objects exhaustively in Experiment 3. In contrast with the results of Kas and Lukács (2013), I did not find an effect of the subject or object role of the focussed element in the case of structural focus in Experiment 2. Turning to the other factor, the within-condition comparisons of various sentences types did not reveal a significant effect of the use of the verbal particle in any of the experiments, as opposed to what has been predicted. This is in line with the findings of Kas and 
Lukács (2013), although the three-point scale used here appeared to be more sensitive in several aspects than the binary judgment they used.

\section{Conclusions}

When comparing the three construction types, different acquisition paths can be found in each case, underscoring the theoretical assumptions of Kenesei (1986) and Szabolcsi (1994), among others. If exhaustivity is conveyed by the at-issue content of sentences (as in the case of csak 'only'), even young children can process it and associate it with the right constituent based on syntactic cues. As predicted, exhaustive inferences with non-at-issue status are harder for them to recognise and distinguish from one another. While the great majority of preschoolers do not seem to be sensitive to these meaning components and also seven-year-olds tend to be uncertain about them, nine-year-olds are able to detect the presupposition encoded by the specific syntactic and prosodic properties of sentences containing structural focus. What is more problematic for this age group is to take contextual factors into account, which presumably triggered the unmotivated implicature generation in the case of sentences with neutral intonation and word order.

\section{Acknowledgements}

I thank all children, parents, kindergartens and schools involved for their cooperation, as well as all the adults who participated in the study. This research was supported by Grant 108951 of OTKA, the Hungarian National Scientific Research Foundation. 


\section{Appendix}

Test sentences of Experiment 1-3 ("exh." = exhaustive, "non-exh." = non-exhaustive, "exh. with distr." = exhaustive with distractor).

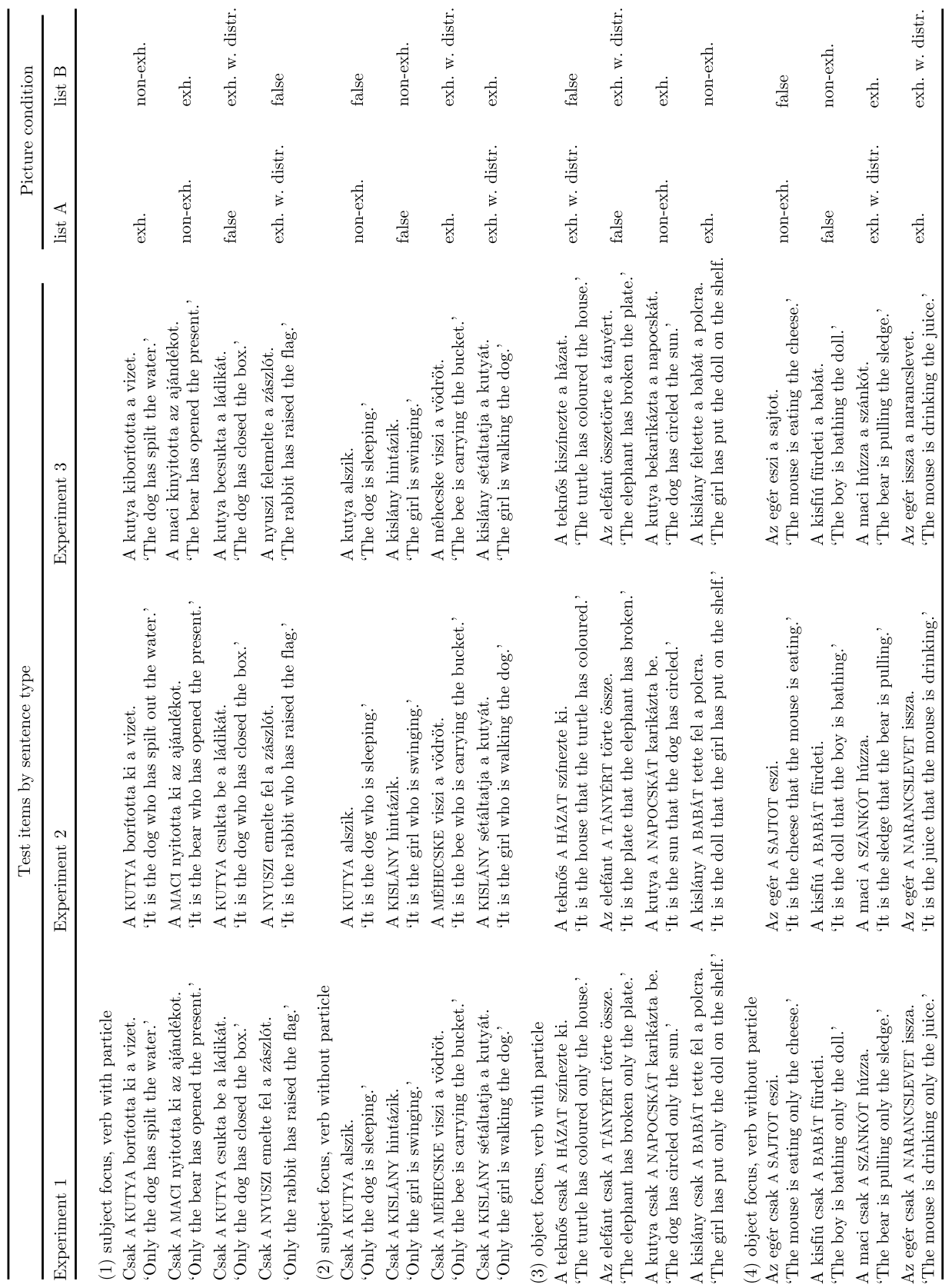




\section{References}

Abusch, Dorit. 2002. Lexical alternatives as a source of pragmatic presuppositions. In B. Jackson (ed.) Proceedings of the 12th Semantics and Linguistic Theory Conference. New York: CLC Publications. 1-19.

Balázs, Andrea and Anna Babarczy. 2014. A felnôttek és a négyévesek ige előtti fókuszos mondat értelmezése [Adults' and four-year-olds' interpretation of sentences with preverbal focus]. Paper presented at Pszicholingvisztikai Nyári Egyetem, Balatonalmádi, Hungary.

Beaver, David and Brady Clark. 2008. Sense and sensitivity. Malden, MA \& Oxford: Blackwell.

Bende-Farkas, Ágnes. 2009. Adverbs of quantification, it-clefts and Hungarian focus. In K. É. Kiss (ed.) Adverbs and adverbial adjuncts at the interfaces (Interface explorations 20). Berlin \& New York: Mouton de Gruyter. 317-348.

Berger, Frauke and Barbara Höhle. 2012. Restrictions on addition: Children's interpretation of the focus particles "auch" 'also' and "nur" 'only' in German. Journal of Child Language 39. 383-410.

Büring, Daniel and Manuel Križ. 2013. It's that, and that's it! Exhaustivity and homogeneity presuppositions in clefts (and definites). Semantics \& Pragmatics 6. 1-29.

Crain, Stephen, Weija Ni and Laura Conway. 1994. Learning, parsing and modularity. In C. Clifton, L. Frazier and K. Rayner (eds.) Perspectives on sentence processing. Hillsdale, NJ: Lawrence Erlbaum. 443-467.

Destruel, Emilie, Daniel Velleman, Edgar Onea, Dylan Bumford, Jingyang Xue and David Beaver. 2015. A cross-linguistic study of the non-at-issueness of exhaustive inferences. In F. Schwarz (ed.) Experimental perspectives on presuppositions. Berlin: Springer. $135-156$.

É. Kiss, Katalin. 1981. Syntactic relations in Hungarian, a "free" word order language. Linguistic Inquiry 12. 185-215.

É. Kiss, Katalin. 1998. Identificational focus versus information focus. Language 74. 245273.

É. Kiss, Katalin. 2010. Structural focus and exhaustivity. In M. Zimmermann and C. Féry (eds.) Information structure. Theoretical, typological and experimental perspectives. Oxford: Oxford University Press. 64-88.

Gazdar, Gerald. 1979. Pragmatics: Implicature, presupposition, and logical form. New York: Academic Press.

Gerőcs, Mátyás, Anna Babarczy and Balázs Surányi. 2014. Exhaustivity in focus: Experimental evidence from Hungarian. In J. Emonds and M. Janebová (eds.) Language use and linguistic structure. Olomouc: Palacký University. 181-194.

Grice, H. Paul. 1975. Logic and conversation. In P. Cole and J. L. Morgan (eds.) Syntax and semantics, vol. 3: Speech acts. New York: Academic Press. 41-58.

Gualmini, Andrea, Simona Maciukaite and Stephen Crain. 2003. Children's insensitivity to contrastive stress in sentences with only. In Proceedings of the 25th Annual Penn Linguistics Colloquium. Philadelphia: University of Pennsylvania Press. 87-110.

Hackl, Martin, Ayaka Sugawara and Ken Wexler. 2015. Question-answer (in)congruence in the acquisition of "only". In E. Grillo and K. Jepson (eds.) BUCLD 39: Proceedings of the 39th annual Boston University Conference on Language Development. Somerville, MA: Cascadilla Press. 204-217. 
Horn, Laurence R. 1969. A presuppositional analysis of "only" and "even". Proceedings of the Annual Meeting of the Chicago Linguistics Society 5. 98-107.

Horn, Laurence R. 1996. Exclusive company: Only and the dynamics of vertical inference. Journal of Semantics 13. 1-40.

Horvath, Julia. 2005. Is "focus movement" driven by stress? In C. Piñón and P. Siptár (eds.) Approaches to Hungarian 9: Papers from the Düsseldorf conference. Budapest: Akadémiai Kiadó. 131-158.

Horvath, Julia. 2007. "Discourse features", syntactic displacement and the status of contrast. Manuscript. Tel Aviv University.

Kálmán, László and Noor van Leusen. 1993. The semantics of free focus. ILLC: Amsterdam.

Karttunen, Lauri. 1974. Presuppositions and linguistic context. Theoretical Linguistics 1. $181-94$.

Kas, Bence and Ágnes Lukács. 2013. Focus sensitivity in Hungarian adults and children. Acta Linguistica Hungarica 60. 217-245.

Katsos, Napoleon and Dorothy V. M. Bishop. 2011. Pragmatic tolerance: Implications for the acquisition of informativeness and implicature. Cognition 20. 67-81.

Kenesei, István. 1986. On the logic of Hungarian word order. In W. Abraham and S. de Meij (eds.) Topic, focus, and configurationality. Amsterdam \& Philadelphia: John Benjamins. 143-159.

Kenesei, István. 2006. Focus as identification. In V. Molnár and S. Winkler (eds.) The architecture of focus (Studies in Generative Syntax 82). Berlin \& New York: Mouton de Gruyter. 137-168.

Komlósy, András. 1994. Complements and adjuncts. In F. Kiefer and K. É. Kiss (eds.) The syntactic structure of Hungarian (Syntax and semantics 27). San Diego/New York: Academic Press. 91-178.

Müller, Anja, Petra Schulz and Barbara Höhle. 2011. How the understanding of focus particles develops: Evidence from child German. In M. Pirvulescu, M. C. Cuervo, A. T. Pérez-Leroux, J. Steele and N. Strik (eds.) Proceedings of the 4th Conference on Generative Approaches to Language Acquisition North America. Somerville, MA: Cascadilla Proceedings Project. 163-171.

Notley, Anna, Peng Zhou, Stephen Crain and Rosalind Thornton. 2009. Children's interpretation of focus expressions in English and Mandarin. Language Acquisition 16. 240-282.

Onea, Edgar. 2007. Exhaustivity, focus and incorporation in Hungarian. In M. Aloni, P. Dekker and F. Roelofsen (eds.) Proceedings of the 16th Amsterdam Colloquium. Amsterdam: ILLC. 169-74.

Onea, Edgar and David Beaver. 2011. Hungarian focus is not exhausted. In S. Ito and E. Cormany (eds.) Semantics and Linguistic Theory (SALT) 19. Ithaca, NY: CLC Publications. 342-359.

Paterson, Kevin B., Simon P. Liversedge, Diane White, Ruth Filik and Kristina Jaz. $2005 / 2006$. Children's interpretation of ambiguous focus in sentences with "only". Language Acquisition 13. 253-284.

Percus, Orin. 1997. Prying open the cleft. In K. Kusumoto (ed.) Proceedings of the 27th Annual Meeting of the North East Linguistic Society. Amherst, MA: GLSA. 337-351.

Potts, Christopher. 2005. The logic of conventional implicatures. Oxford: Oxford University Press. 
R Development Core Team. 2014. R: A language and environment for statistical computing. Vienna: Foundation for Statistical Computing. http://www.R-project.org

Roberts, Craige. 2011. "Only": A case study in projective meaning. In B. H. Partee, M. Glanzberg and J. Skilters (eds.) Formal semantics and pragmatics: Discourse, context and models. Manhattan, KS: New Prairie Press. 1-59.

Rooij, Robert van and Katrin Schulz. 2007. "Only": Meaning and implicatures. In M. Aloni, A. Butler and P. Dekker (eds.) Questions and answers. Amsterdam: Elsevier. 193-224.

Skopeteas, Stavros and Gisbert Fanselow. 2011. Focus and the exclusion of alternatives: On the interaction of syntactic structure with pragmatic inference. Lingua 121. 1693-1706.

Sperber, Dan and Deirdre Wilson. 1986. Relevance: Communication and cognition. Cambridge, MA \& Oxford: Blackwell.

Surányi, Balázs. 2011. A szintaktikailag jelöletlen fókusz pragmatikája [On the pragmatics of syntactically unmarked focus]. Általános Nyelvészeti Tanulmányok 23. 281-313.

Szabolcsi, Anna. 1981a. Compositionality in focus. Folia Linguistica 15. 141-161.

Szabolcsi, Anna. 1981b. The semantics of topic-focus articulation. In J. Groenendijk, T. Janssen and M. Stokhof (eds.) Formal methods in the study of language. Amsterdam: Mathematisch Centre. 503-540.

Szabolcsi, Anna. 1994. All quantifiers are not equal: The case of focus. Acta Linguistica Hungarica 42. 171-187.

Velleman, Dan, David Beaver, Emilie Destruel, Dylan Bumford, Edgar Onea and Elizabeth Coppock. 2012. It-clefts are IT (Inquiry Terminating) constructions. In A. Chereches (ed.) Proceedings of the 22nd Semantics and Linguistic Theory Conference, held at the University of Chicago in Chicago, Illinois, May 18-20, 2012. Washington, DC: Linguistic Society of America. 441-460.

Wedgwood, Daniel. 2005. Shifting the focus. From static structures to the dynamics of interpretation. Amsterdam: Elsevier.

Wilson, Deirdre and Dan Sperber. 2004. Relevance theory. In L. R. Horn and G. Ward (eds.) The handbook of pragmatics. Oxford \& Malden, MA: Blackwell. 607-632.

Zhou, Peng and Stephen Crain. 2010. Focus identification in child Mandarin. Journal of Child Language 37. 965-1005. 
